\title{
Nådens tuttar. Om skönheter, odjur och den frälsande kvinnokroppen i modern romance
}

\author{
Maria Nilson
}

Våren 2017 blev Bill Condons version av Disneys Beauty and the Beast en av de mest populära filmerna och drog mängder av människor till biograferna (Tartaglione 2017). Filmen är en omarbetning av Disneys populära tecknade version från 1991 och dess popularitet verkar antyda att historien om den unga skönheten som räddar odjuret fortfarande är en som lockar oss. I följande artikel ska jag diskutera denna historia, hur den går från folksaga till bästsäljande fenomen, hur den är en viktig del av genren romance, men hur den också utvecklas och förändras. Färden går från Madame de Beaumonts klassiska version av Skönheten och odjuret från 1756 till Disneys tolkning där jag valt att arbeta med romanversionen av den senaste filmen till Stephanie Meyers Twilight (2005) och E.L. James Fifty Shades of Grey (2011) och min ambition är att visa exempel på och problematisera hur vi fått nya versioner av både "skönheter och odjur” och hur dessa kan tolkas.

Att vi gång på gång återvänder till folksagor och omtolkar dem ur olika perspektiv är ingen nyhet. I dagens populärkultur finns det ett flertal exempel på nya tolkningar av folksagor, som inte sällan är både mörka och våldsamma (Nilson 2013). I barnlitteraturen hittar vi naturligtvis också en rad exempel på nya versioner av folksagor, och det finns en diger forskning kring folksagomotiv för barn och unga. ${ }^{1}$ Omskrivningar av folksagor och folksagomotiv är också ett viktigt inslag i romance, men här finns det än så länge få akademiska studier, då mycken romanceforskning har fokuserat på att beskriva genren i sin helhet och vi först nu ser mer detaljorienterade studier (se exempelvis Goris 2012). Då Skönheten och odjuret är en viktig intertext för romance är det intressant att studera dels hur den återkommer i olika skepnader i genren, dels hur den hela tiden omtolkas. Jag kommer i denna artikel främst diskutera hur Skönheten i olika texter förvandlats från den goda, dygdiga unga kvinnan som frälser Odjuret då hennes godhet inspirerar och transformerar honom, till den sexuellt lockande kvinnan, som förvandlar Odjuret då han åtrår henne och inte kan få henne om han inte ändrar på sig.

Inledningsvis vill jag diskutera och problematisera genren romance. Det finns tyvärr inget fungerande svensk begrepp för romance. Romantik blir missvisande och romantiska berättelser blir alltför brett. Romance i denna artikel hänvisar till en specifik populärlitterär

\footnotetext{
${ }^{1}$ Se exempelvis antologin Cinderella across Cultures. New Directions and Interdisciplinary Perspectives (2016) Red. Martine Hennard Dutheil de la Rochère, Gillian Lathey, \& Monika Woźniak (Detroit: Wayne State University Press) där olika versioner av Askungen för barn diskuteras ur en rad olika perspektiv och kontexter. Se också antologin Fairy Tales with a Black Consciousness. Essays on Adaptations of Familiar Stories (2013). Red. Vivian Yenika-Agbaw, Ruth McKoy Lowery och Laretta Henderson (London: McFarland) där artiklarna behandlar, bland annat, etnicitet och rasism i välkända folksagor återberättade för barn.
} 
genre, där omskrivningar och nytolkningar av folksagor är påfallande vanliga. Jag kommer sedan att börja färden från Beamonts Skönhet till den vi möter i James erotiska romance.

\section{Vad är romance?}

När Barbara Fuchs i boken Romance (2004) försöker att kartlägga begreppet, börjar hon med att konstatera att det är en osedvanligt spretig etikett. Fuchs skriver: "[T]he term is variously applied to everything from Spenser's The Fairy Queen, to Shakespeare's plays, to seventeenth century French classicizing fiction, to Harlequin romances”. (s. 4f) Mitt intresse är den version av romance som i mycket dominerar populärlitteraturen idag och som de flesta fortfarande främst associerar till Harlequin-romaner. I boken Kärlek, passion och begär. Om romance (2015) diskuterar jag genren mer utförligt, men den vanligaste förekommande definitionen av genren är den som Romance Writers of America (RWA) ligger bakom:

A Central Love Story - In a romance, the main plot concerns two people falling in love and struggling to make the relationship work. The conflict in the book centres on the love story. The climax of the book resolves the love story. A writer is welcome to as many subplots as she likes as long as the relationship conflict is the main story.

An Emotionally Satisfying and Optimistic Ending - Romance novels end in a way that makes the reader feel good. Romance novels are based on the idea of an innate emotional justice - the notion that good people in the world are rewarded and evil people are punished. In a romance, the lovers who risk and struggle for each other and their relationship are rewarded with emotional justice and unconditional love. (Fuchs 2004: 124f, mina kursiveringar)

I mycken romance dominerar de lyckliga sluten och godhet lönar sig. Naturligtvis utvecklas denna genre och förändras, som alla genrer, men vissa beståndsdelar "måste” vara med för att en text ska kunna kallas romance. Att en kärlekshistoria måste finnas med är de flesta överens om, men det finns olika åsikter om ett lyckligt slut är absolut nödvändigt.

Det har under årens lopp kommit flera försök att kartlägga genren. Ett av de tidigaste är Janice Radway som i Reading the Romance (1984) definierar tretton narratologiska steg som hon menar kännetecknar genren, som exempelvis: " 1 . The Heroine's social identity is destroyed, 2. The Heroine reacts antagonistically to an aristocratic male, 3.The aristocratic male responds ambiguously to the heroine etc” (Radway 1984: 134). Idag är Radways romance-forskning tämligen ifrågasatt, bland annat för att hennes underlag dels visat sig bestå av få romaner, dels fokuserat på en enda subgenre inom romance, nämligen historisk romance. Det är snarare Pamela Regis åtta element från A Natural History of the Romance Novel (2003) som forskare utgår från. Regis skriver att:’These eight essential narrative events provide a romance novel with its basic structure. Without these, the work is not a romance novel” (2003: 38). De åtta elementen ramar in vad vi kan kalla romance-intrigens grundplåt med en inledande konflikt, ett flertal möten mellan hjälte och hjältinna, hinder och missförstånd och avslutningsvis ett lyckligt slut. Samtidigt blir det problematiskt att beskriva en gigantisk och växande genre med ett fastlåst schema. Jayashree Kimblé menar i Making Meaning in Popular Romance Fiction. An Epistemology (2014) att "In order to avoid treating the entire genre as static and monolithic, it is valuable to remember that romance fiction is a novelistic genre, adapting itself repeatedly over time” (2014: 24). I sin studie där hon går igenom hundratals Harlequin-romaner, undviker Kimblé att vaska fram en slags blåkopia 
över genren, utan fokuserar istället på dominerande drag, samtidigt som hon gång på gång påpekar att romanernas motsägelsefullhet. Å ena sidan är romanerna till stor del fyllda med både traditionella och stereotypa genusmönster, men å andra sidan innehåller de i påfallande hög grad också teman där kvinnan blir "den starkare”, där det är hjältinnans projekt som är det viktiga och där maktförhållandet mellan kvinnor och män på olika sätt problematiseras.

Det senaste försöket jag läst där en forskare försöker "fånga in" romance-genren är Catherine M. Roachs Happily Ever After. The Romance Story in Popular Culture (2016) där hon fokuserar på ett av mest bärande elementen i genren, nämligen föreställningen om att vi alla vill leva i en monogam relation och alla har en själsfrände, en "one true love” som nästan per automatik kommer att göra en lycklig. "The romance genre belives in this religion of love” (2016: 170).

Idag finns det ett flertal underkategorier inom genren. Meyers Twilight kan exempelvis kallas både för "teen romance" och "paranormal romance" samtidigt som James Fifty Shades of Grey ofta får epitetet "erotic romance”. Samtidigt är dessa underkategorier i mycket rätt arbiträra och handlar kanske mer om att bokförlag ska kunna marknadsföra sina böcker än om böckernas innehåll. Jag kommer att utgå från ett brett romance-begrepp, där även vad vi skulle kunna kategorisera som en "barnkultur” ingår, nämligen Disneys Beauty and the Beast vars popularitet jag redan nämnt. Det kan vara viktigt att påpeka att denna version inte endast tilltalat en yngre publik, utan också en vuxen.

\section{Skönheter och odjur i romance}

Som all annan skönlitteratur existerar naturligtvis inte romance i ett vacuum utan påverkas och influeras av både en samtida kontext och ett kulturarv. Folksagans motiv med dess fokus på prövningar där den rättrådiga och goda karaktären belönas med ett lyckligt slut har influerat genren och det är inte överraskande att genren i hög grad lånar motiv från just folksagor. $^{2}$ När Laura Vivanco i For Love and Money försöker definiera romance, påpekar hon att dagens romance utnyttjar och lånar från ett västerländskt kulturarv. I romance möter man ofta omskrivningar av allt från sagan om Askungen till nya versioner av Pygmalionmyten (Vivanco 2011: 79ff). Vivanco skriver om genren att:”Like a superstitious bride, every romance novel thus combines elements of the old, the new, the borrowed and the blue” (Vivanco 2011: 21). Om det är lätt att hitta nya versioner av både Askungen och Törnrosa i mycken romance, är det ännu vanligare med nya versioner av just sagan om Skönheten och Odjuret.

När Jay Dixon diskuterar decennier av Mills \& Boons ${ }^{3}$ romaner och påpekar hur hjälten och hjältinnan skildrats och skildras menar hon emellertid att ett av de vanligaste återkommande temana är att hjälten är både äldre och rikare än hjältinnan och att han måste förvandlas, räddas och transformeras innan de kan få varandra.

\footnotetext{
${ }^{2}$ Under de senaste åren har det blivit allt vanligare i romance med omskrivningar av välkända folksagor som Eloisa James When Beauty Tamed the Beast (2011) och A Kiss at Midnight (2012). Samtidigt kan det vara värt att nämna att denna fäbless för att skriva nya versioner av folksagor finns i en rad andra genrer också, som exempelvis fantasy och ungdomsdystopier, se Nilson 2013, s. 99ff.

${ }^{3}$ Förlaget Mills \& Boon skapades redan 1909 och fick en tidig framgång med just romance. Från början hade alla böckerna liknande omslag och kallades "the brown books". Genom att satsa på billiga pocket böcker med enkla omslag lyckades Mills \& Boon växa och är idag, precis som Harlequin en stor koncern (Dixon 1999).
} 
In this respect, Mills \& Boon romance have more in common with The Beauty and the Beast fairy tale, than with the story of Cinderella. In these books, even if the 'Prince' is wealthier and more powerful than the heroine, he still has to undergo a sea-change in order to become worthy of her. (Dixon 1999: 61)

I romance har det alltså ofta handlat om att en grubblande, olycklig och ofta rätt odräglig hjälte, behöver "räddas" av en ung hjältinna och förändras för att det lyckliga slutet ska kunna nås. Samtidigt som det lyckliga slutet inte sällan innebär att hjältinnan exempelvis får det bättre ekonomiskt, ligger fokus ändå mer på det centrala temat från Skönheten och odjuret än på Askunge-temat.

Hjälten i romance har ofta varit en så kallad alfaman som är stark och mäktig, men samtidigt sårbar och olycklig. Evelyn Sullerot skriver i en underhållande bok med titeln Women on Love. Eight Centuries of Feminine Writing att:

With a kiss, we women tirelessly transforms bears, swine, big bad wolfs into men worthy in our eyes of the name of men [...] She (the heroine) is responsible for the second birth of this man, through the magic sentiment that she inspires in him, she transforms him and cures him merely by touching him. (Sullerot 1979: 20f)

Sullerot är något viktigt på spåret här. Å ena sidan är det hjältinnans inre egenskaper, hennes godhet som gör att hon kan förvandla hjälten, men å andra sidan är denna förvandling endast möjlig via hennes kropp.

Samtidigt som hjälten måste förändra sig för att bli värdig hjältinnan, är det vanligt att romance-hjältinnan behöver initiera denna förändring. Detta tolkas av forskare som Regis och Kimblé som ett av de element som har lockat kvinnor till att läsa romance. Samtidigt som genrens hjältinna ofta inledningsvis befinner sig i ett underläge gentemot hjälten, är det till slut hon som räddar honom och som möjliggör det lyckliga slutet, vilket har tolkats som ett feministiskt drag (Regis 2003, Kimblé 2014). ${ }^{4}$

Om vi börjar med att diskutera den förändring som skett, är det tacksamt att exemplifiera med en författare som Nora Roberts, som sedan början på 1990-talet skrivit över tvåhundra romaner och är en av de romance-författare som i åratal översatts till svenska. Hennes romaner ges ut både av Albert Bonniers Förlag och av Harlequin och hon har sålt bokstavligen miljontals böcker. I sin bok A Natural History of the Romance Novel ägnar Pamela Regis ett kapitel åt Nora Roberts och diskuterar ett flertal exempel från Roberts tidiga produktion där vi känner igen ett Skönheten och Odjuret-tema (Regis 2001: 183ff). Hjälten är ensam och ofta besviken på livet och på kvinnorna, han är inte sällan arrogant, men samtidigt sårbar och hjältinnan räddar honom från isolering och känslolöshet, samtidigt som han räddar henne från maffiabossar och seriemördare. Men i senare verk av Roberts, som exempelvis Jagad av lögnen (2012) är det snarare hjältinnan som är den emotionellt sårade som behöver

\footnotetext{
${ }^{4}$ Romance är en genre med låg status, vilket naturligtvis även påverkar forskningen om den. Linda J. Lee menar i artikeln "Guilty Pleasures: Reading Romance Novels as Reworked Fairytales” att romanceforskare lätt hamnar i två olika grupper: "Most scholarship on romance novels falls into one of two polarized camps that view these novels as conservative forms that uphold existing patriarchal structures, or as subversive resisting forms that challenge existing structures” (Lee 2008: 54). Jag kan tycka att Lee har en poäng och onekligen hamnar ibland både Regis och Kimblé i en försvarande position. Samtidigt är det omöjligt att som forskare undvika att förhålla sig till den status genren har.
} 
räddas och helas av hjälten. I dag är det vanligt med hjältinnor som "gett upp” kärleken och som bär på mörka hemligheter och som inte längre behöver räddas från maffiabossar (de klarar av dem själva) men de behöver hjälp att våga lita på en annan människa igen och att tro på kärleken. Skönheten och odjuret finns fortfarande kvar, men det är hon som är Odjuret och han som är den frälsande Skönheten.

Varför har då just temat med en skönhet som frälser/räddar ett odjur varit så viktigt inom romance? Jag skulle argumentera för att det handlar om maktbalansen mellan hjälte och hjältinna. Catherine Roach skriver i artikeln: "Getting a Good Man to Love: Popular Romance Fiction and the Problem of Patriarchy” att i romance är hjälten både en krigare och någon som hjältinnan behöver ta hand om, men framför allt är han trogen:

The romance fantasy, in other words, is that the hero will come, in all his fierce and possessive patriarchal warrior - king glory, but that he will also forever stay: emotionally vulnerable, devoted unto death, serving his mistress with his sword and his heart. (Roach 2010: opaginerad)

Samtidigt som denna alfaman är just en alfaman och i och med detta, stark, smart och skicklig, är han också sårbar och för evigt tacksam mot den hjältinna som "räddat” honom. Idag ser vi en ny stark trend i romance med jämställda par där ingen dominerar den andre, men det går inte att sticka under stol med att i mycken romance har vi haft hjältar som i stort och smått fått sin vilja igenom och som ofta haft både mer muskelstyrka, mer pengar och mer makt än hjältinnan. I roman efter roman har hjältinnor behövts räddas men eftersom hjältarna också varit i behov av frälsning, har den ojämna maktbalansen justerats en aning. Han har behövt henne lika mycket som hon har behövt honom.

Innan jag går vidare vill jag ge några exempel på hur dessa omskrivningar av folksagan kan se ut. Ett exempel är, som nämnts, Eloisa James When Beauty Tamed the Beast (2011) där historien är placerad under Regency-epoken. Odjuret är enstöringen Piers som efter att ha fått sitt hjärta krossat, lever isolerad på sitt gods i Wales. Skönheten är den unga Linnet som är fast besluten att "rädda” honom, vilket i denna version innebär att få honom att tro på kärleken igen. Ett liknande tema finner vi i Hannah Howells Beauty and the Beast (1992) som utspelar sig under 1300-talet. Här tvingas den unga och vackra Gytha gifta sig med "the red devil”, den ärrade Thayer som i likhet med James hjälte, också fått sitt hjärta krossat av en manipulerande kvinna. Samtidigt som intrigerna på ytan har rätt lite att göra med själva folksagan, är temat det samma och romantitlarna naturligtvis inte valda på måfå. Läsaren kan, med hjälp av paratexten, få en förståelse för vad romanen ska komma att handla om. Ett tredje exempel som riktar sig till yngre läsare är Wendy Mass Twice Upon A Time. Beauty and The Beast (2012) med undertiteln The Only One Who Didn't Run Away. Denna roman ligger närmare sagan än de tidigare, men är en nytolkning som friskt blandar element från en rad olika sagor och där skönheten snarare utmärks av att vara ovanligt klipsk, än av att vara vacker och/eller god. Här handlar det mer om att hjältinnan behöver rädda hjälten än att hon behöver tämja honom. 


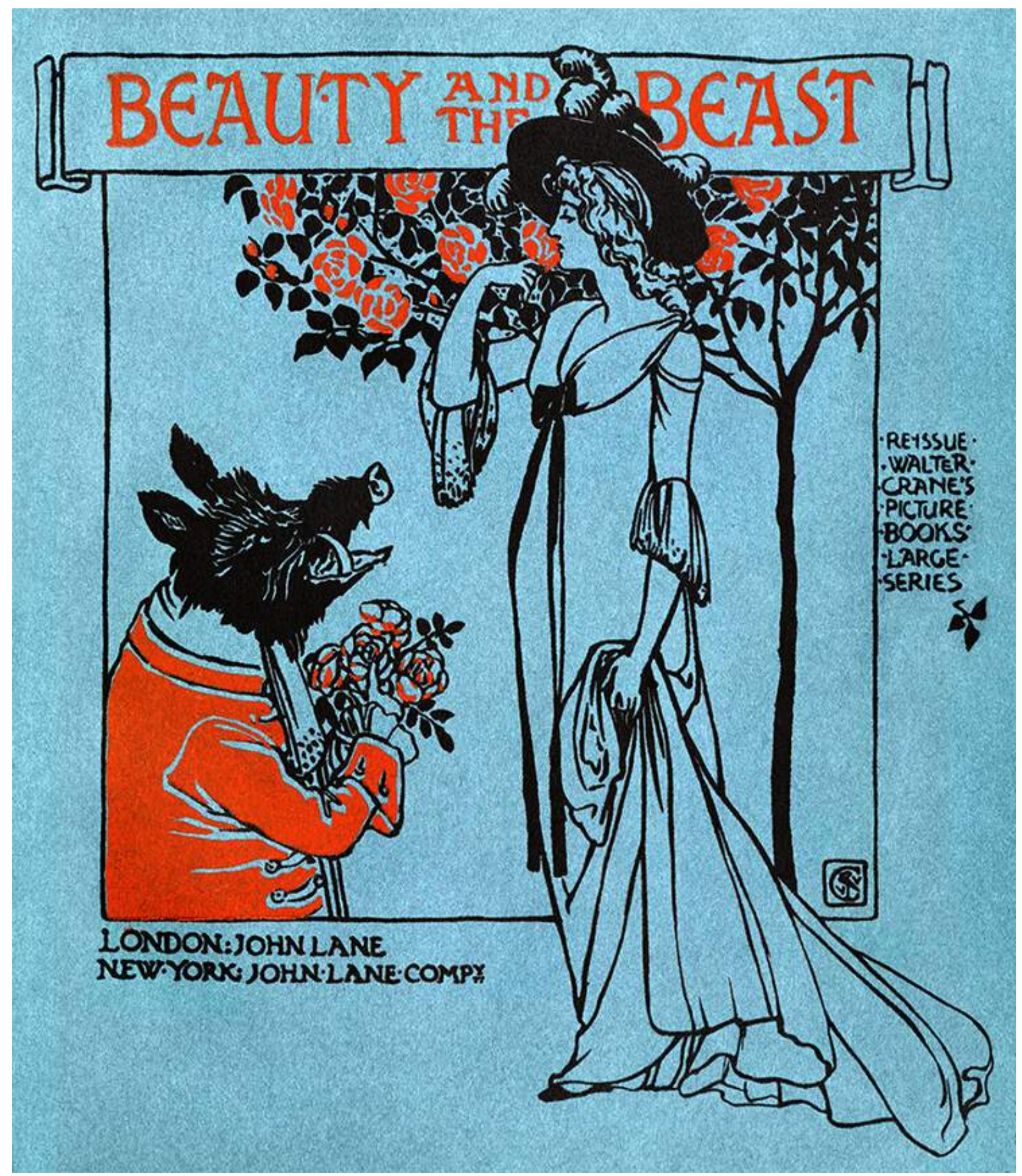

Bild 1

\section{En Skönhet från 1700-talet}

Den mest kända versionen av Skönheten och odjuret är Madame de Beaumonts version från 1756, publicerad i hennes Magasin des Enfants. Denna version kan med viss försiktighet kallas för en "urtext" till många av de moderna omskrivningarna jag diskuterar, då det naturligtvis finns andra tidiga versioner av sagan som exempelvis bröderna Grimms, samtidigt som just Beaumonts version verkar vara den mest spridda.

I denna version är det didaktiska perspektivet viktigt. Barnen skulle lära sig något av historierna de läste (Tatar 2017: xii). Skönheten är i denna version en av tre systrar, men i 
motsats till systrarna som är själviska och elaka, är hon alltigenom god: "The youngest, as she was handsome, was also better than her sisters” (de Beaumont 2003: opaginerad). Systrarna drömmer om materiellt välstånd och när fadern ger sig av på en resa, vill de ha smycken och kläder, medan Skönheten endast vill ha en ros. Fadern hamnar efter en storm i Odjurets slott och tas väl om hand, han får äta sig mätt och sova ut, men naturligtvis slutar besöket illa. När fadern fängslas av Odjuret efter att ha plockat en ros i hans trädgård för att ge till sin yngsta dotter, är Skönheten genast redo att ge upp sitt liv för honom. "I will deliver myself up to all his fury, and I am very happy in thinking that my death will save my father's life, and be proof of my tender love for him” (de Beaumont 2003: opaginerad). Skönheten offrar sig själv för att rädda sin far som återvänder hem, men Odjuret dödar henne inte, utan behandlar henne som en ärad gäst istället och efter en tid, kommer hon att se honom som något annat än ett odjur. Hon ser hans inre själ.

Among mankind, (says Beauty) there are many that deserve that name more than you, and I prefer you, just as you are, to those, who, under a human form, hide a treacherous, corrupt, and ungrateful heart. (de Beaumont 2003: opaginerad)

Odjuret friar gång på gång till henne, men då hon inte älskar honom, tackar hon nej. Det är inte förrän hon blivit lurad av sina systrar att stanna hemma längre än hon lovat och Odjuret blir dödligt sjuk av längtan, som Skönheten inser att hon älskar honom. Hon lovar att gifta sig med honom och han förvandlas till en ståtlig prins och får ett lyckligt slut, värdigt vilken romance-roman som helst. "The prince married Beauty, who lived with him for a long time in perfect happiness, for their marriage was founded on virtue" (de Beaumont 2003: opaginerad). Systrarna förvandlas i en version till statyer och tvingas att resten av sina liv beskåda Skönhetens lyckliga liv.

Vad är det då som utmärker Skönheten? Jo, hennes "virtue” som på svenska ofta översätts med "dygd", vilket kan bli en smula missvisande. Här handlar det om mer än att vara god, lydig och oskuld. Tatar skriver i sitt förord till samlingen Beauty and the Beast. Classic Tales About Animal Brides and Grooms from Around the World att: "What makes Beauty virtuous? To begin with, she seems possessed of a yen for acts of self-sacrifice" (Tatar 2017: xiii). Skönheten är osjälviskheten personifierad och genom att gång på gång sätta andras behov framför sina egna, lär hon Odjuret att göra detsamma. Men denna version av sagan bär med sig ett dubbelt budskap.

In a move rare in fairytale worlds, it gives us a double trajectory in its standard version; a cursed Beast in search of redemptive love, and a captive Beauty who discovers that essences transcends appearances. (Tatar 2017: ix)

Skönheten frälser Odjuret genom sin godhet, sin moraliska inre kompass och sin osjälviskhet, och lär sig under tiden att skönhet kan finnas under ytan.

Beaumonts version av sagan är riktad till barn och här finns inga inslag som ens andas att vare sig Skönheten eller Odjuret har en sexualitet. 


\section{Disneys version}

Det är intressant att jämföra den klassiska versionen av sagan med en av de senaste, nämligen Disneys version från 2017 där filmmanuset också getts ut som bok med samma titel: Beauty and the Beast (2017). I det följande utgår jag från denna bok. Samtidigt som den på många plan följer den klassiska sagan finns det naturligtvis skillnader. Här får vi en bakgrundshistoria till varför Odjuret blivit ett odjur. Prinsen är självisk och grym och bryr sig endast om sina egna behov. Till skillnad från den tecknade versionen från 1991, ger denna en förklaring i att prinsen tidigt förlorar sin mamma och uppfostras av en brutal och grym far (Disney 2017: 150). ${ }^{5}$ I denna version av folksagan är Belle (som Skönheten heter här) ett enda barn och vi skonas från systrarnas straff i slutet av sagan. Och precis som i den tecknade versionen från 1991, fokuseras det mer på Belle. Om Skönheten i den äldre versionen är fullkomligt nöjd med att stanna hemma resten av sitt liv och ta hand om sin far, vill Belle något mer. Hon läser och drömmer sig bort från den småstad hon lever i där hon inte passar in.

Redan innan Odjuret trätt in på scen, inser vi att det finns olika sorters odjur. Belle är den enda i den lilla isolerade franska staden som ser Gaston för vad han är. Alla andra antingen beundrar eller älskar honom:"But she just couldn't stand the man. There was something beastly about him” (Disney 2017:32). Här blir också temat att se en inre skönhet betydligt tidigare presenterat än tidigare.

Precis som i Madame de Beamonts version är Belle omedelbart redo att ge upp sitt liv för att rädda sin far men här tar det inte lång tid innan hon börjar se på Odjuret med andra ögon. Belle ser för första gången Odjuret: "She felt a strange pang of what was almost sympathy for the giant creature" (Disney 2017: 77). Odjuret visar sig vara en gästfri värd, han läser Shakespeare och lär sig snart att både konversera och roa henne. Och Belle veknar. ”She no longer shuddered if he accidently brushed her with his paw" (Disney 2017: 162). Här finns en antydning av erotik och även om Belle och Odjuret vare sig smeker eller kysser varandra, innan förvandlingen skett, finns här en sexuell spänning mellan dem. Precis som i tidigare versioner av sagan är det inte förrän Odjuret lärt sig att sätta andras behov framför sina egna och låtit henne gå och på grund av det är på väg att dö, som Belle inser att hon älskar honom. Här är emellertid inte Odjuret döende på grund av ett brustet hjärta utan för att Gaston knivhuggit honom. Belle hinner fram innan han drar sitt sista andetag och de kysser varandra:

It was a kiss Belle would never forget - one better than any in all the books she had read. It was a kiss full of apology, full of thankfulness, and full of deep, deep love. It was a kiss full of enchantment. And as their lips met, the magic exploded from them to the rest of the castle. (Disney 2017: 240)

Odjuret förvandlas till en ståtlig prins, förbannelsen hävs över slottet och sedan kan de leva lyckliga i alla sina dagar.

\footnotetext{
${ }^{5}$ Samtidigt får vi i denna bok från 2017 en förklaring till varför tjänarna i slottet också förvandlats i denna version. Mrs Potts förklarar för Belle att de straffas för att de aldrig ingrep och skyddade prinsen från hans våldsamma far.
} 


\section{Odjuret som vampyr}

Även om Disneys version av Skönheten och Odjuret blivit en stor succé, är framgången endast en susning jämfört med den som "fenomenet" Twilight haft. När Stephanie Meyers första roman Twilight kom 2005 blev den mycket snabbt dels ett bästsäljande fenomen, dels en startpunkt för en våg av vampyrberättelser för ungdomar som följde ett liknande mönster. Amy Billone menar i The Future of the Nineteenth-Century Dream-Child att Meyers romaner kom helt rätt i tid och fångade upp en hel generation som vuxit upp med Rowlings Harry Potter och nu var redo för något nytt (Billone 2016: 91). I Bokprovningen ${ }^{6}$ från 2008 konstateras att vampyrer tillsammans med dystopier dominerar bland ungdomslitteraturen: "Vanligast förekommande är de eleganta, sorgset vackra vampyrerna som besitter alla egenskaper som uppskattas i vårt samhälle, med undantag för själva kosthållningen" (Bokprovningen 2008: 4). Med Anna Höglunds terminologi förvandlades vampyrerna från monster till humanvampyrer som å ena sidan ofta bar på ett Nietzsche komplex, men å andra sidan ofta drömde om sin förlorade mänsklighet. Höglund skriver:

I vår samtid har vampyrmannen transformerats från hänsynslös kvinnotjusare med smak för våldsam och perverterad sex, till asketisk romantiker som törstar efter intimitet och den sanna, äkta kärleken. (Höglund 2009: 333)

Vampyren har blivit en av de grubblande olyckliga hjältarna som behöver frälsas/helas/räddas av en Skönhet till hjältinna.

Hur ser då sagan om Skönheten och Odjuret ut i Twilight? Edward är definitivt ett odjur och här är det Bellas blod som inledningsvis lockar honom. I Meyers oavslutade roman Midnight Sun som släpptes på nätet berättas historien ur Edwards perspektiv och hans första reaktion när han träffar Bella är just begär efter hennes blod. "I was a vampire, and she had the sweetest blood I'd smelled in eighty years" (Meyer 2008: 10). Bella förstår inte att han lockas av henne, utan tror att hon på något sätt fyller honom med avsmak. "He was glaring down at me again, his black eyers full of revulsion” (Meyers 2015: 17). Även om Bella längre fram i trilogin kommer att hjälpa Edward att återfå en del av sin mänsklighet, är hon i början av deras relation ett hot, eftersom hon helt enkelt luktar oemotståndligt och Edward vill bita henne. Redan från början finns det en sexuell spänning mellan dem och det är ju begär som från början initierar deras relation. Billone påminner oss i sin analys om att Stephen King gav Meyers serie etiketten "tweenager porn" (Billone 2016: 93). Edward vill gärna dricka Bellas välsmakande blod och hon tycker han är nästan oemotståndligt attraktiv. Att Edward är ett Odjur är tydligt redan från början. "'What if I'm not the superhero? What if I'm the bad guy?' He smiled playfully, but his eyes were impenetrable" (Meyers 2015: 63). Men även när Bella inser att Edward är en vampyr som törstar efter hennes blod, kan hon inte undgå att älska honom.

Twilight är i mycket paranormal romance och här finns spår efter flera välkända folksagor. Sara Buttsworth menar i artikeln "CinderBella. Twilight, Fairy Tales, and the Twenty-FirstCentury American Dream" att just Askungesagan är väsentlig i Meyers trilogi. Bella går från att vara sheriffens dotter till att bli prinsessa och får inte bara rikedom utan även evigt liv

\footnotetext{
${ }^{6}$ Bokprovningen är den årliga genomgång som Svenska Barnboksinstitutet gör av all barn- och ungdomslitteratur som ges ut i Sverige.
} 
(Buttsworth 2010). Här finns ett Snövit-tema och definitivt ett starkt Skönheten och Odjurettema, men det är inte Skönhetens dygd, hennes oskuldsfullhet som inledningsvis lockar Odjuret, utan här har vi ett Odjur som mer drivs av begär, först efter Skönhetens blod och sedan efter hennes kärlek. Samtidigt finns det en hel del spår efter folksagans Skönhet även i Bella. I Midnight Sun får Edward konstatera att Mike, en i gänget av alla unga män som trånar efter Bella, inte alls ser vem Bella är:

He hadn't observed the unselfishness and bravery that set her apart from other humans; he didn't hear the abnormal maturity of her spoken thoughts. He didn't perceive that when she spoke of her mother, she sounded like a parent speaking of a child rather than the other way around. (Meyer 2008: 92f)

Plötsligt blir Bella en rätt traditionell version av Skönheten då Odjuret inte bara lockas av hennes kropp (blod) utan också av hennes osjälviskhet och hennes vilja att offra sig för andra.

Samtidigt är det intressant att se hur vi kan tolka Skönheten på olika sätt. Billone plockar i sin analys av Twilight också upp folksagan, men påpekar också hur Emily Brontës Wüthering Heights är en viktig intertext i romanen. I hennes analys blir Skönheten den starka och aktiva:

To what extent is Belle a triumphant heroine like 'Beauty' might be in a revised modernized version of the fairy tale 'Beauty and the Beast'? To what extent is she a victim who inheritad her name from the utterly frail and even pathetic Isabella Linton? (Billone 2016:101)

När Billone alluderar till Skönheten med epitetet “triumphant” påminner hennes analys i mycket den som romance-forskare som Regis och Kimblé presenterar där hjältinnan som räddar ett Odjur till hjälte beskrivs som stark, aktiv och nästan feministisk.

\section{En Skönhet att piska}

E.L. James Fifty Shades of Grey (2011) har precis som Twilight blivit en bästsäljare utan like och lett till en våg av erotisk romance (Nilson 2015: 103ff). James började sin författarbana med att skriva fan fiction kopplad till Twilight trilogin och den första versionen av Fifty Shades of Grey publicerades på nätet under titeln "Master of the Universe”. James trilogi är i mycket en hybrid där flera olika genrer blandas, men många (mig själv inkluderad) läser den främst som romance.

These books are unabashedly romantic. They follow the tried-and-true formula for romance and the series end happily. And, as previously stated, this would hold true even if aliens came down and vacuumed all the sex out of all the copies in existence. With that in mind, there can be no denying that the Fifty Shades series is a romance. (King 2012:78)

Och precis som i mycken annan romance finns här tydliga spår av folksagor. Även här finns ett Askunge motiv då den unga Ana dras in i en glamourös värld av Christian som också öser dyra presenter över henne. Hon går på ett sätt från att vara collegestudent till att bli prinsessa. Men här finns också ett tydligt Skönheten och odjuret tema. Katherine Ramsland menar att James romaner definitivt är romance, och tycker att de innehåller vad hon tolkar som en typisk "kvinnlig” fantasi: 
Women of all ages are drawn to the Beauty and Beast archetype found in the Fifty Shades trilogy, where the strength of a man's love is measured by his willingness to restrain his aggression. It's the ultimate female fantasy. (Ramsland 2012: 214)

Att Christian är ett Odjur är rätt snabbt etablerat i trilogin. Han är den rika multimiljonären som bestämmer över tusentals anställda och han gör tidigt klart för Ana att det är han som bestämmer. I Fifty Shades of Grey menar han att "I'm used to getting my own way, Anastasia', he murmured. 'In all things'” (James 2012: 44). Detta gäller även i personliga relationer där han inledningsvis kräver att Ana ska skriva på ett kontrakt och bli hans sexslav. Istället för att bli irriterad, fascineras Ana av hans dominanta sida. "I’m paralyzed with a strange, unfamiliar need, completely captivated by him” (James 2012: 49). Den första boken avslutas med att Ana lämnar honom då hon inte står ut med att han blir sexuellt upphetsad av att slå henne, men det dröjer inte många sidor in i del 2 Fifty Shades Darker innan de är tillsammans igen. Och i denna del blir det än mer tydligt att Christian både är ett Odjur och ser sig själv som ett Odjur. 'I’m a sadist, Ana. I like to whip little brown-haired girls like you because you all look like the crack whore - my birthmother" (James 2012: 329). Samtidigt är det tydligt att Christian precis som Odjuret i Disneys film har blivit ett Odjur på grund av tidigare erfarenheter. Christians mamma beskrivs som en drogmissbrukare och prostituerad och det antyds att hennes kunder förgripit sig på Christian då han var barn. ${ }^{7}$ Christian behöver helas och här träder Ana in som Skönheten. Men hur helar Ana honom?

Precis som i Twilight inleds deras relation av ett ömsesidigt begär. Hon som är oskuld och aldrig tidigare varit särskilt intresserad av sex, dras omedelbart till Christian. Och han som inte kan tänka sig att ha sex utan kontrakt (och handklovar) har plötsligt "vaniljsex”. "’'I’ve never had vanilla sex before. There's a lot to be said for it. But then, maybe it's because it's with you”, (James 2012: 132) säger Christian efter han och Ana haft sex tillsammans för första gången. Ana beskrivs som oskuldsfull och naiv, men här är det egentligen varken hennes osjälviskhet eller hennes vilja att uppoffra sig som Christian dras till, utan snarare hennes vilja att underkasta sig, hennes barnsliga sätt att se på världen och naturligtvis hennes unga och åtråvärda kropp.

Till skillnad från många av hans tidigare relationer, lyder inte Ana honom i allt. När Ana inte går med på att underteckna kontraktet, godtar Christian detta för att hålla relationen vid liv. Samtidigt är det påfallande vanligt förekommande i trilogin att Ana gör något som retar Christian och han "straffar" henne med BDSM-sex. I tredje delen, Fifty Shades Freed blir Ana gravid och Christian vill inte ha barnet. "Diapers and vomit and shit!” (James 2012: 418). Han ser barnet som något som kommer att inkräkta på deras relation, något som kommer att dra Anas uppmärksamhet bort från honom och han blir genast irriterad över den nu illamående Ana inte vill leka i "det röda rummet” längre. Det är egentligen först här som Ana sätter ned foten och skäller ut honom: "But you're an adult now - you need to grow up and smell the fucking coffee and stop behaving like a petulant adolescent” (James 2012: 434). För Ana är det självklart att barnet måste komma först. När Christian inser att han riskerar att förlora Ana, ändrar han sig och vi når det lyckliga slutet. Å ena sidan kan man

\footnotetext{
${ }^{7}$ I Grey från 2015 berättar E. L James samma historia som i Fifty Shades of Grey, men denna gång ur Christians perspektiv och i denna roman är det mer fokus på hans traumatiska minnen från barndomen.
} 
läsa detta som att Ana lär honom empati, men å andra sidan är det i texten mer fokus på att han inte vill ge upp Ana än på att han vill bli far.

\section{Avslutning}

Som jag tidigare varit inne på har romance, som vilken annan genre, förändrats och utvecklats under årens lopp. Dess hjältinnor har fått mer skinn på näsan, dess hjältar har blivit mindre arroganta och maktfullkomliga och maktförhållandet mellan dem börjar att förändras. Samtidigt är vissa motiv fortfarande ofta återkommande och ett av dessa är Skönheten och Odjuret. I både paranormal romance och erotisk romance tycker jag mig se en version av Skönheten där hennes styrka, hennes möjlighet att förändra och frälsa hjälten allt tydligare kopplas till hennes kropp. Hon förändrar hjälten då han vill ha henne och då han inser att han måste ändra på sig för att hon ska göra sin kropp tillgänglig. Hon går från att vara godheten personifierad till att bli något som hjälten attraheras av och om det är hennes "själ” eller "rena hjärta” som räddar och frälser hjälten i tidiga versioner, är det idag i vissa fall snarare hennes åtråvärda kropp, vilket artikeltiteln anspelar på. Att kvinnor reduceras till ”kroppar” är på inget sätt något nytt, utan detta exempel måste naturligtvis läsas som ett av många.

I paranormal romance finns det gott om romaner där en mänsklig kvinna räddar en vampyr, varulv eller fallen ängel. I erotisk romance med dagens intresse för BDSM-sex är det betydligt vanligare att hon är den underdåniga och han är den som bestämmer. Rent krasst är det ont om kvinnor som är Odjur utan vår roll verkar fortfarande vara att agera Skönhet. Samtidigt som det onekligen går att läsa in en styrka, en slags agens i att frälsa/rädda ett odjur och nå det lyckliga slutet och samtidigt som både en Edward och en Christian i Meyers och James versioner till syvende och sist längtar lika mycket efter kärlek som efter sex, finns det något både intressant och problematiskt i hur Skönhetens styrka i dessa moderna versioner i så hög grad ligger i att hjälten åtrår hennes attraktiva kropp. Samtidigt som Skönheten i Beaumonts klassiska version naturligtvis speglar en både ålderdomlig och stereotyp föreställning av den unga kvinnan som "ren och god” med en inre moralisk kompass, speglar Skönheten hos exempelvis James en minst sagt lika stereotyp föreställning där kvinnans styrka tycks till stor del vila på att hjälten attraheras av hennes kropp.

\section{Referenser}

Beaumont, Madame de (2003) Beauty and the Beast, https://www.gutenberg.org/ files/7074/7074.txt [170601]

Billone, Amy (2016), The Future of the Nineteenth-Century Dream-Child. Fantasy, Dystopia, Cyberculture. New York, London: Routledge.

Bokprovning (2009), årgång 2008. Svenska Barnboksinstitutet. http://www.sbi.kb.se/sv/ Bokprovning/Dokumentation/ [170304]

Buttsworth, Sara (2010), ”CinderBella. Twilight, Fairy Tales, and the Twenty - First Century American Dream”, i Nancy R. Reagin (red.), Twilight and History. Hoboken: John Wiley \& Sons, s. 47-69.

Hennard Dutheil de la Rochère, Martine, Gillian Lathey \& Monika Woźniak (2016), Cinderella across Cultures. New Directions and Interdisciplinary Perspectives. Detroit: Wayne State University Press. 
Disney (2017), Beauty and the Beast. Book of the Film. Adapted by Elizabeth Rudnick. Screenplay by Evan Spiliotopoulas, Stephen Chbosky och Bill Condon, Bath: Parragon Books.

Dixon, Jay (1999), The Romance Fiction of Mills \& Boon. 1909 - 2000. New York: Routledge.

Yenika-Agbaw, Vivian, Ruth McKoy Lowery och Laretta Henderson (red.) (2013), Fairy Tales with a Black Consciousness. Essays on Adaptations of Familiar Stories. London: McFarland.

Fuchs, Barbara (2004), Romance. London, New York: Routledge.

Goris, An (2012), "Mind, Body, Love: Nora Roberts and the Evolution of Popular- Romance Studies”, Journal of Popular Romance Studies, 3.1.

Howell, Hannah (1992), Beauty and the Beast. New York: Zebra Historical Romance.

Höglund, Anna (2009), Vampyrer. En kulturkritisk studie av den västerländska vampyrberättelsen från 1700-talet till 2000-talet. Växjö: Växjö University Press.

James, E. L. (2012), Fifty Shades of Grey, Fifty Shades Darker, Fifty Shades Free (samlingsvolym). New York: Vintage Books.

James, Eloisa (2011), When Beauty Tamed the Beast. New York: Avon Books.

Kimblé, Jayashree (2014), Making Meaning in Popular Romance Fiction. An Epistemology. Basingstoke: Palgrave MacMillan.

King, D.L. (2012), “Is Fifty Shades Erotica?”, I Lori Perkinbs (red.), Fifty Writers on Fifty Shades of Grey. Dallas: Benbella Books, s. 43 - 49.

Lee, Linda (2008), "Guilty Pleasures: Reading Romance Novels as Reworked FairyTales”, Marvels \& Tales: Journal of Fairy Tale Studies, vol.22, no.1.

Mass, Wendy (2012) Twice Upon a Time. Beauty and the Beast. The Only One Who Didn't Run Away, New Tork: Scholastic Inc.

Meyer, Stephanie (2015) Twilight/Life and Death. Twilight Reimagined. New York: Little, Brown and Company

Meyer, Stephanie (2008) Midnight Sun. Partial draft. http://stepheniemeyer.com/project /midnight-sun/ [161104]

Nilson, Maria (2015) Kärlek, passion och begär - om romance. Lund: BTJ Förlag.

Nilson, Maria (2013) Teen Noir. Om mörkret i modern ungdomslitteratur. Lund: BTJ Förlag.

Radway, Janice (1984) Reading the Romance. Women, Patriarchy and Popular Literature. North Caroline: University of North Carolina Press.

Ramsland, Katherine (2012) "Being Stretched. The Risk and Riches of a 'LimitExperience’”. Fifty Writers on Fifty Shades of Grey. red. Lori Perkins. Dallas: Benbella Books, s. 213- 220.

Regis, Pamela (2003) A Natural History of the Romance Novel, Pennsylvania: University of Pennsylvania Press.

Roach, Catherine M. (2016) Happily Ever After. The Romance Story in Popular Culture, Indiana: Indiana University Press.

Roach, Catherine M. (2010) "Getting a Good Man to Love: Popular Romance Fiction and the Problem of Patriarchy”, Journal of Popular Romance Studies, 1.1., http://jprstudies. org/2010/08/getting-a-good-man-to-love-popular-romance-fiction-and-the-problem-ofpatriarchy-by-catherine-roach/ [170103]

Roberts, Nora (2012) Jagad av lögnen, översatt av: Ylva Stålmarck, (Chasing Fire), Stockholm: Alberts Bonniers Förlag.

Sullerot, Evelyn (1979) Women on Love. Eight Centuries of Feminine Writing, London: Doubleday. 
Tartaglione, Nancy (2017) “"Beauty And The Beast’ Enchants \$900M At WW Box Office; Crosses \$400M Domestic”, http://deadline.com/2017/04/beauty-and-the-beast-crosses900-million-worldwide-box-office-400-million-domestic-1202062137/ [170602]

Tatar, Maria (2017) “Introduction: The Odd Couple in Tales as Old as Times”, i Maria Tatar (red.), Beauty and the Beast. Classic tales About Animal Brides and Grooms from Around the World. London: Penguin Books.

Tatar, Maria (red.) (2017), Beauty and the Beast. Classic tales About Animal Brides and Grooms from Around the World. London: Penguin Books.

Vivanco, Laura (2011) For Love and Money. The Literary Art of Harlequin Mills \& Boon Romance, Penrith: Humanities - Ebooks.co.uk

\section{Bildförteckning:}

Bild 1: Omslag av Walter Crane

https://www.oldbookillustrations.com/illustrations/beauty-beast-cover/ [20171023] 